\title{
RIVER OTTER DISTRIBUTION AND FOOD HABITS IN Grand Teton NATIONAL PARK AS PART OF AN ONGOING PROJECT IN THE GYE
}

\author{
ASSESSING THE POTENTIAL OF THE RIVER OTTER (LONTRA CANADENSIS) TO PROMOTE \\ AQUATIC CONSERVATION IN THE GREATER YELLOWSTONE ECOSYSTEM: \\ A UNIQUE APPROACH FOR DEVELOPING A LONG-TERM AQUATIC FLAGSHIP
}

\author{
Kelly J. PEARCE $\uparrow$ UNIVERSITY OF MARYLAND \\ CENTER FOR ENVIRONMENTAL SCIENCE $\uparrow$ FROSTBURG, MD \\ TOM L. SERFASS $\uparrow$ FROSTBURG STATE UNIVERSITY $\uparrow$ FROSTBURG, MD
}

\begin{abstract}
$+\quad$ ABSTRACT
Grand Teton National Park is part of the known range of the North American river otter, however not much is known about this semi-aquatic mammal within the park. The results presented here are part of a larger project to investigate the potential of the river otter (Lontra canadensis) to serve as an aquatic flagship (species that engender public support and action) for the Greater Yellowstone Ecosystem. River otters, known for their charismatic behavior have the potential to serve as an aquatic flagship species to promote conservation of aquatic ecosystems. The primary objective of this portion of the study was to identify river otter latrines on portions of the Snake River, between Flagg Ranch and Jackson Lake, and between Jackson Lake Dam and Pacific Creek, collect river otter scats to determine diet of the river otter, and employ remote cameras to determine activity patterns of the river otters. Between 20 June and 1 July 2015, 26 river otter latrines were identified during shoreline surveys, 186 river otter scats were collected, and cameras were deployed at 6 latrines between 7 July and 24 August 2015. River otter scats have been cleaned and prepared for analysis, but have not all been processed to date. Camera traps recorded 222 images, of which 7\% $(n=14)$ were of carnivores, $70 \%(n=155)$ were of non-carnivore mammals, and $9 \%(n=22)$ were of birds. River otters were detected at 1 of the 6 latrines, a total of 5 independent times during the study.
\end{abstract}

\section{$\uparrow \quad$ INTRODUCTION}

The North American river otter (Lontra canadensis) is a semi-aquatic mammal that was historically distributed throughout the conterminous United States and Alaska, but faced severe declines throughout many parts of its range from overharvest, disturbance to riparian habitats (e.g., deforestation) and various forms of water pollution (Hall 1981, Melquist and Dronkert 1987, Kruuk 2006). Through natural expansion of remnant populations and reintroduction projects in 22 states, the river otter now occupies at least portions of its historic range in each state (Bricker et al. 2015). In Wyoming, the river otter was extirpated from most of the state, except the Greater Yellowstone Ecosystem (GYE), but is currently known to occupy the western two-thirds of the state, with a stable-expanding population (Keinath 2003, Wyoming Game and Fish Department 2010, Bricker et al. 2015). In the GYE, part of the known range of the river otter includes Grand Teton National Park (GRTE).

This proposed research is an extension of a project which began in GRTE during the summer of 2014: Assessing the potential of the river otter (Lontra canadensis) to promote aquatic conservation in the Greater Yellowstone Ecosystem: A unique approach for developing a long-term aquatic flagship (Pearce and Serfass 2014). We have developed a conceptual framework to guide our ongoing evaluation of the 
following aspects of the species to determine its prospective value as an aquatic flagship species: 1) public support, 2) viewability, 3) public education and involvement, and 4) protocols for long-term monitoring.

During summer 2014, we began initial evaluation (step 1 of the above framework) of the potential for the river otter to serve as a flagship species for the GYE by conducting social science surveys with visitors to GRTE who were participating in guided-raft trips on the Snake River, and Oxbow Bend, a popular turn-out for viewing aquatic wildlife, including river otters. We conducted additional surveys in the Trout Lake parking lot in Yellowstone National Park (YELL) during the summer of 2015 to determine visitor attitudes towards the environment in general, and specifically the river otter and its habitat, and assess if different direct exposure types to the river otter (i.e., observing the river otter in wild, in captivity, or both), or indirect exposure to marketing materials about the species influences behavioral intentions to conserve the river otter and its habitat (Pearce and Serfass 2016).

The primary objective of this part of the study was to evaluate step 2 of the framework-visibility. Specifically, our objectives for this portion of the project were to: 1) identify river otter latrines along portions of the Snake River between Flagg Ranch and Jackson Lake and between Jackson Lake Dam and Pacific Creek and Flagg Ranch (Figure 1), and 2) collect scats at latrines for later diet analysis of river otters in GRTE and determine size of prey.

\section{$\uparrow \quad$ MeTHODS}

\section{Data collection}

Between 20 June and 1 July 2015, 26 river otter latrines were identified during shoreline surveys along portions of the Snake River, north of Jackson Lake, and between Jackson Lake Dam and Pacific Creek (Figures 1 and 2). Latrines were classified as active based on the presence of fresh otter scat deposits. Fresh river otter scats were collected from latrines, stored in a plastic bag, labeled, and frozen until analysis. In preparation for analysis, scats were washed by soaking overnight in soapy water, then rinsed through a sieve to eliminate organic material and other debris. After drying, food particles were separated to facilitate identification of scales, exoskeletons and other undigested prey remains.

Six of the river otter latrines were selected as sites for placement of camera traps (Figure 3).
Cuddeback Attack ${ }^{\odot}$ cameras were secured to a tree using straps or attached with straps to metal stakes $(150 \times 5.08 \times 5.08 \mathrm{~cm})$, if a tree was unavailable. Camera trapping occurred from 7 July to 21 August 2015 for a total of 216 camera trap-days (defined as the sum of days [24-hr period] each camera was operational). Camera traps were checked every 7 days to replace SD cards, batteries (if necessary), and perform any other needed maintenance. Camera traps at latrines were programmed to take 1 image after a trigger with a 30-second delay. All camera traps were set at low sensitivity to extend battery life. Date and time were automatically recorded by cameras on to each image, and all images were sorted and organized based on Sanderson and Harris (2013).

\section{Data analysis}

Remains were identified to the species or family using Daniels (1996) scale identification key and reference collection of scales and other bony structures. Prey items were recorded by frequency of occurrence, determined by tabulating the number of scats the prey occurred in and dividing by the total number of scats.

All images were summarized by species and location, and classified images as temporally independent if a lapse of $>60$ min occurred between 2 images of the same species at a site.

\section{$\uparrow \quad$ PRELIMINARY RESUltS}

Twenty-six river otter latrines were identified (Figure 2). A total of 186 scats were collected during regular visits to latrines. Scats have been cleaned in preparation for analysis. To date, 3 fish families have been identified in the scats, including Catostomidae, Salmonidae, and Cyprinidae, but not all scats have been processed.

Camera trapping occurred between 7 July and 24 August 2015 for a total of 216 camera trapdays. Camera traps recorded 222 images, of which $7 \%$ $(n=14)$ were of carnivores, $70 \%(n=155)$ were of non-carnivore mammals, and $9 \%(n=22)$ were of birds. We could not determine species in 14\% $(n=31)$ of the photographs due to poor lighting, angle or if species was too far or close to camera. Species captured on photographs included 4 carnivore species (river otter, red fox [Vulpes vulpes], coyote [Canis latrans], and black bear [Ursus americanus]), 2 cervidaes (elk [Cervus canadensis], mule deer [Odocoileus hermionus]), 1 accipitridae (bald eagle [Haliaeetus leucocephalus]), 2 species of anseriformes (Canada goose [Branta canadensis] and 
common merganser [Mergus merganser], one gruiformes (sandhill crane [Grus canadensis]), one pelicaniformes (great blue heron [Ardea Herodias]), and one passeriformes (Common raven [Corvus corax]).

River otters were detected at 1 of the 6 latrines a total of 5 independent times during the study. The group size ranged from 1-8 otters visiting the site at one time. On average, $3.8( \pm 2.78 \mathrm{SD})$ river otters were detected at a time at the latrine. River otters exhibited primarily diurnal behavior at the latrine site. They were detected at the latrine sites at 5 different times, 01:23, 06:01, 08:12, 09:12, and 23:42.

\section{$\downarrow$ MANAGEMENT IMPLICATIONS}

Based on our preliminary results, river otters in Grand Teton National Park appear to exhibit unique behaviors unlike river otters in other riverine systems. Specifically, the river otters we detected formed large groups, and were active during daylight hours. These results are consistent with another study on river otter behavior that was conducted in GRTE by Hall (1986). These results indicate that river otters may be viewable to visitors of GRTE, an essential characteristic of a successful flagship species.

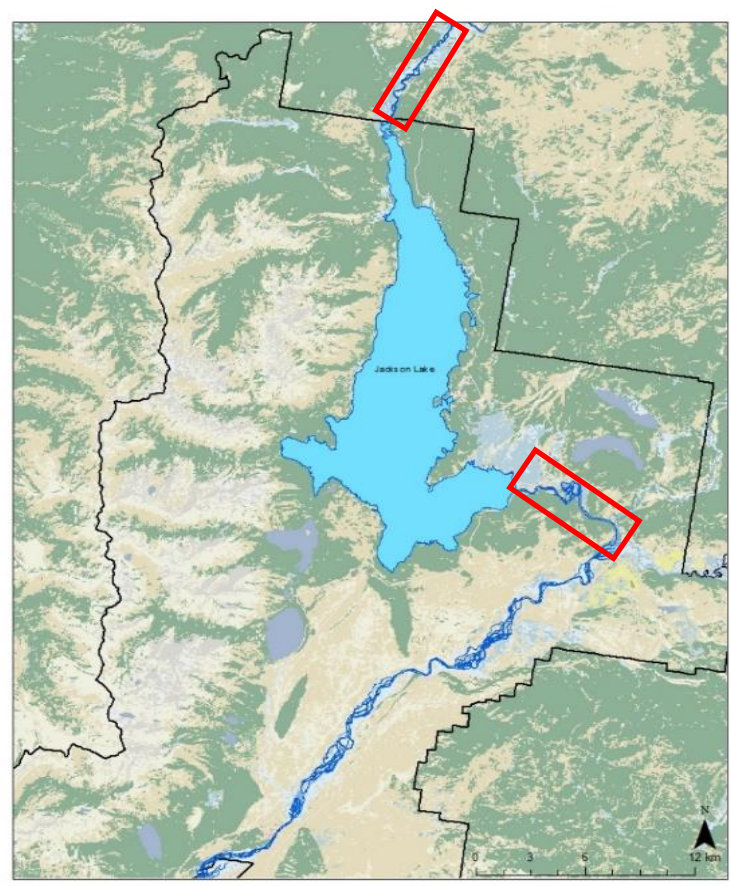

Figure 1. Surveys for river otter latrines were conducted along portions of the Snake River, Grand Teton National Park between Flagg Ranch and Jackson Lake, and between Jackson Lake Dam and Pacific Creek from 20 June and 1 July 2015.

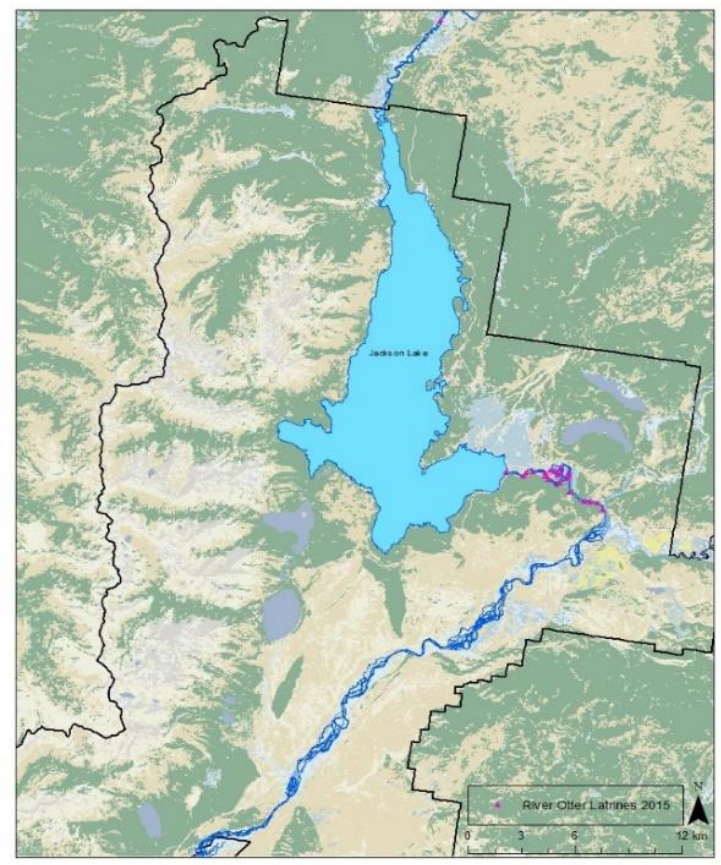

Figure 2. Twenty-six river otter latrines were identified along portions of the Snake River, Grand Teton National Park, between Flagg Ranch and Jackson Lake, and between Jackson Lake Dam and Pacific Creek from 20 June and 1 July 2015.

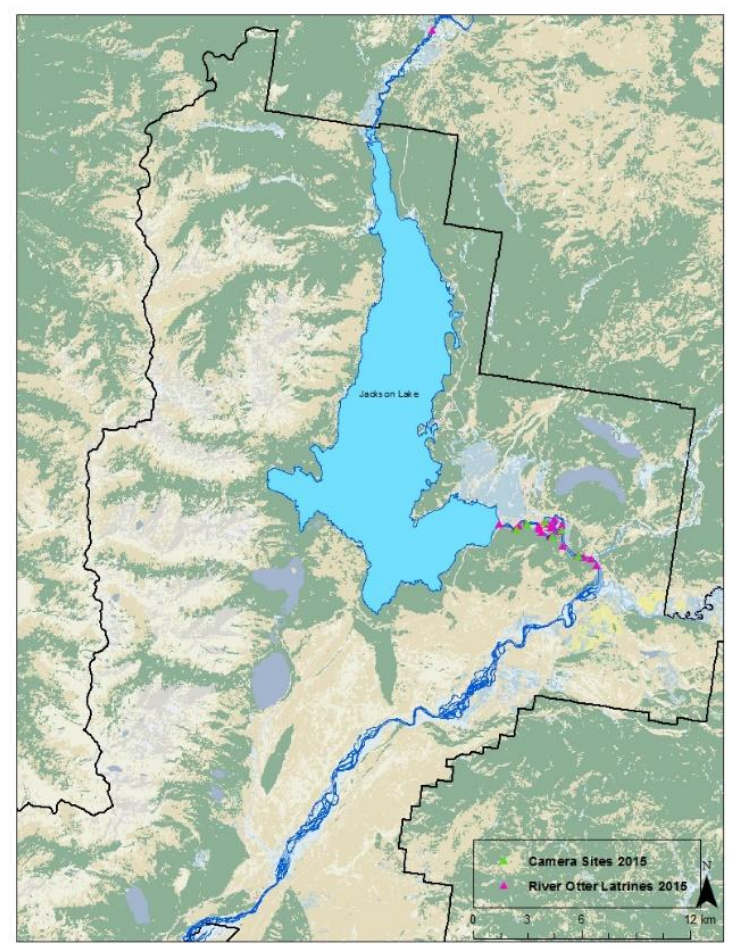

Figure 3. Six latrines were selected for camera-trapping which occurred from 7 July to 21 August 2015 for a total of 216 camera trap-days. River otters were detected at 1 of the 6 latrines during the study. 


\section{$\downarrow$ ACKNOWLEDGEMENTS}

Support for this study was provided by Frostburg State University. This research would not have been possible without the great assistance of Marie Tosa who helped conduct all field work. Thanks to Bec Cotton, Ian Hopkins, Callahan Job, and Toni Proescholdt for their help with field work and camera monitoring. We would also like to thank Sarah Dewey from GTRE for permit and logistical assistance, the UW-NPS Research Station for letting us use the kayaks during field research. Our sincere thanks go out to Harold Bergman and Gordo Richman for logistical assistance and equipment loans associated with the field work and great conversations.

\section{$\downarrow \quad$ Literature Cited}

Bricker, E.A., T.L. Serfass, F.K. Ammer, Z.L. Hanley, K.J. Pearce, and S.S. Stevens. In Press. Conservation status of the North American river otter (Lontra canadensis) in the United States and Canada: Management practices and public perceptions of the species. E.D. Linh San, J.J. Sato, J.L. Belant, and M.J. Somers (eds.). Small Carnivores: Evolution, Ecology, Behavior and Conservation. In Press.

Daniels, R.A. 1996. Guide to the identification of scales of inland fishes of northeastern North America. New York State Mus. Bull. No. 488. The University of New York. Albany, New York. 97pp.

Hall, E.R. 1981. The Mammals of North America. Second Edition. John Wiley and Sons, New York, New York. 1373 pp.

Hall, J.G. 1984. Ecological study of river otters in Grand Teton National Park. University of Wyoming National Park Service Research Center Annual Report. 6:9.
Keinath, D.A. 2003. Bat and terrestrial mammal inventories in the Greater Yellowstone Network. University of Wyoming National Park Service Research Center Annual Report. 27:15.

Kruuk, H. 2006. Otters: Ecology, Behavior, and Conservation. Oxford University Press, Inc., New York, USA.

Melquist, W.E., and A.E. Dronkert. 1987. River otter. Pp 626-641, In: M. Novak, J.A. Baker, M.E. Obbard, and B. Malloch (eds.). Wild Furbearer Management and Conservation in North America. Ontario Ministry of Natural Resources, Toronto, Canada.

Melquist, W.E., and M.G. Hornocker. 1979. Methods and techniques for studying and censusing river otter populations - Technical Report 8. Wildlife and Range.

Melquist, W.E., and M.G. Hornocker. 1983. Ecology of river otters in west central Idaho. Wildlife Monographs 83:1-60.

Pearce, K.J., and T.L. Serfass. 2014. Assessing the potential of the river otter (Lontra canadensis) to promote aquatic conservation in the Greater Yellowstone Ecosystem: A unique approach for developing a long-term aquatic flagship. University of Wyoming National Park Service Research Center Annual Report. 37:108-113.

Pearce, K.J., and T.L. Serfass. 2016. Influence of the river otter on formation of conservation intentions in the Greater Yellowstone Ecosystem. University of Wyoming National Park Service Research Center Annual Report. In Press.

Wyoming Game and Fish Department. 2010. Wyoming State Wildlife Action Plan Species Accounts: Northern River Otter (Lontra canadensis) 2:52-53. 